\title{
P65 A Beat-to-Beat Quality Indicator Based on Piecewise Spatiotemporal Estimates of Carotid Pulse Wave Velocity Improves Correlation with Pulse Pressure
}

\author{
Fabian Beutel ${ }^{1,2}$, Van Hoof Chris ${ }^{2,3}$, Evelien Hermeling ${ }^{1}$ \\ ${ }^{1}$ imec, Eindhoven, The Netherlands, \\ ${ }^{2}$ KU Leuven, Leuven, Belgium, \\ ${ }^{3}$ imec, Leuven, Belgium
}

\section{ABSTRACT}

Background: Local carotid pulse wave velocity (PWV) estimation is challenging due to a complex anatomy and associated wave reflections [1]. Wave interference is both blood pressure (BP) and position dependent, hence causing nonlinearity in the spatiotemporal PWV estimation [2]. In lack of beat-to-beat quality assessment [3], we propose a method to quantify this nonlinearity and thereby introduce a quality indicator (QI) for reliable PWV estimation.

Methodology: Carotid artery ultrasound (Vantage64, VerasonicsInc., USA) was acquired from 10 subjects (38 \pm 10 years) in six repeated measurements. Simultaneously, ECG (ECG100C, BIOPACInc., USA) and noninvasive BP (NOVA, FinapresMedicalSystems B.V., NL) were recorded. Signals were processed into distension waveforms to extract systolic foot (SF) and dicrotic notch (DN) fiducials [4]. Beat-to-beat PWV estimates at SF (PWVSF) and DN (PWVDN) were obtained via spatiotemporal fitting of respective fiducial timings against transducer element distances. The proposed nonlinearity QI was quantified as standard deviation of the error between full-length PWV estimate and piecewise PWV estimates from the proximal, middle and distal subset of transducer elements. Linear regression was performed between independent pulse pressure (PP, in 2 [mmHg] intervals) and dependent PWV (means of all estimates) to validate QI according to Bramwell-Hill [5].

Results: When qualifying PWV estimates with QI $\leq 1[\mathrm{~m} / \mathrm{s}]$ we observed a significant $R^{2}$ increase for both PWVSF $(0.22$ to 0.41 , with decreased RMSE from 0.47 to $0.42[\mathrm{~m} / \mathrm{s}])$ and PWVDN $(0.21$ to 0.53 , although with constant RMSE of 0.32 [m/s]) as shown in annexed figure.

Conclusion: The proposed beat-to-beat QI accounts for significant variability in the PWV-PP relation, albeit at substantial data reduction. Therefore, the QI may facilitate real-time quality assessment towards reliable local PWV estimation. The unexplained variability remainder requires further investigations for confounding variables.
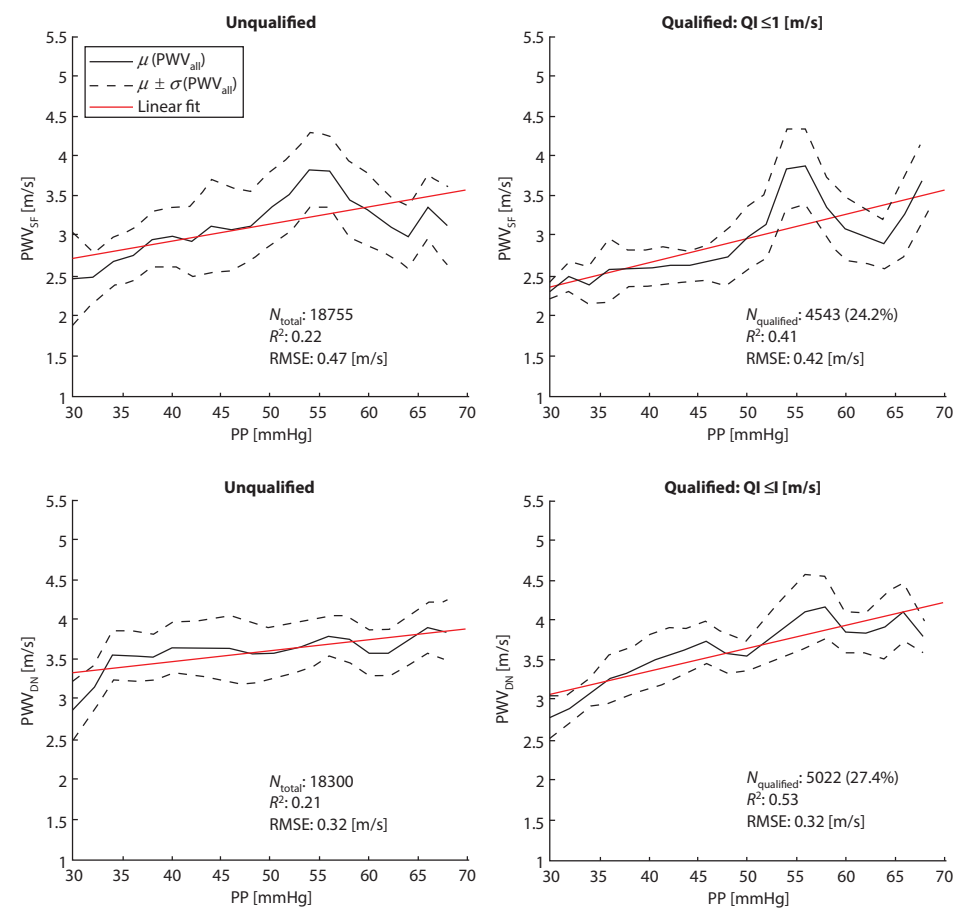


\section{REFERENCES}

[1] Swillens A, Taelman L, Degroote J, Vierendeels J, Segers P. Comparison of non-invasive methods for measurement of local pulse wave velocity using FSI-simulations and in vivo data. Ann Biomed Eng 2013;41:1567-78.

[2] Hermeling E, Reesink KD, Reneman RS, Hoeks AP. Confluence of incident and reflected waves interferes with systolic foot detection of the carotid artery distension waveform. J Hypertens 2008;26:2374-80.

[3] Hermeling E, Reesink KD, Hoeks AP, Reneman RS. Potentials and pitfalls of local PWV measurements. Am J Hypertens [Internet] 2010;23:935.

[4] Beutel F, Mansilla Valle L, Van Hoof C, Hermeling E. End-diastolic wall position reset in long-term carotid artery motion tracking yields robust distension waveforms (Abstract Submitted to ARTERY19). 2019.

[5] Bramwell J, Hill A. The velocity of pulse wave in man. Proc R Soc Biol Sci 1922;93:298-306

(C) 2019 Association for Research into Arterial Structure and Physiology. Publishing services by Atlantis Press International B.V. This is an open access article distributed under the CC BY-NC 4.0 license (http://creativecommons.org/licenses/by-nc/4.0/). 